\title{
MÍDIAS, CULTURA E FORMAÇÃO*
}

\author{
Cleide Aparecida Carvalho Rodrigues \\ Universidade Federal de Goiás, Goiânia, Goiás, Brasil \\ Daniela da Costa Britto Pereira Lima \\ Universidade Federal de Goiás, Goiânia, Goiás, Brasil
}

\begin{abstract}
Resumo: Este artigo resulta de pesquisa bibliográfica desenvolvida pelas autoras no Grupo de Estudos e Pesquisas Novas Tecnologias e Educação (Gente), da Faculdade de Educação da Universidade Federal de Goiás, do qual participam, e tem como propósito refletir sobre a possibilidade de os estudantes de Pedagogia relacionarem os diversos aspectos teóricos que envolvem as mídias com as vivências culturais que possuem com elas, para, posteriormente, pensar pedagogicamente essa relação. Essa reflexão baseia-se em um conceito múltiplo de mídias: como "meios de comunicação" e matrizes culturais; como cultura relacionada com um sistema de significados e com a imagem de construção da identidade; e como formação humana, que se estabelece na relação entre o formal e o informal e por meio das diferentes linguagens. Enfim, buscou-se refletir essa trilogia a partir da relação teoria-prática das vivências culturais midiáticas em processos de formação docente.
\end{abstract}

Palavras-chave: Mídias. Cultura. Formação docente.

INÍCIO DE CONVERSA

A cibercultura, tanto quanto quaisquer outros tipos de cultura, são criaturas humanas. Não há uma separação entre uma forma de cultura e o ser humano. Nós somos essas culturas. (SANTAELLA, 2003, p. 24)

Os estudos que tratam da trilogia Educação, Mídias e Formação têm apresentado desdobramentos em relação à produção cultural das mídias e aos processos de formação, especificamente a de professores.

* Artigo recebido em 7/3/2014 e aprovado em 5/5/2014. 
Consideramos neste artigo que o agir comunicacional dos processos de formação emerge nas interfaces entre os campos da educação e da comunicação. Com esse entendimento, partimos para a reflexão acerca do conceito de mídias como "meios de comunicação"e matrizes culturais, ou seja, a cultura relacionada com o sistema de significados, organização e construção da identidade. A formação humana é aqui entendida como um processo que ocorre nas relações entre o formal e informal, o visível e o invisível e que se manifestam por meio das linguagens do corpo, sejam elas intelectivas, físicas, emocionais e/ou subjetivas.

A trilogia proposta nesta reflexão - mídias, cultura e formação - tem como convergência a relação entre a teoria e as práticas de vivências digitais em processos de formação docente.

\section{CONCEITOS: MÍDIAS E CULTURA NA CONSTITUIÇÃO HUMANA}

É comum o entendimento de mídias como meios de comunicação de massa (rádio, jornal, revistas, internet, TV a cabo); tecnologia (TV, computador, telefone, outros); suporte (CD, pendrive, livro, outdoor, cartazes, folders, panfletos e outros); ferramenta (microfone, autofalante, jogos, software e outros); consumo (inovação); ou entretenimento, informação, cultura. São mídias que também confluem nos processos formativos, tanto societários quanto educativos. Mas qual é o seu conceito? Qual a sua confluência com a educação intencional (formal e não formal) e não intencional (informal)?'

Para estudiosos da comunicação, como Guareschi (2008), as mídias constroem a realidade quando selecionam os fatos que serão veiculados ou não, e qual conotação lhes será dada, o que influencia comportamentos e gera a dimensão de valores. Além disso, para esse autor, "os meios de comunicação pautam a agenda do que o povo pode ver, ouvir e falar. A grande maioria das conversas do dia a dia é agendada pela mídia, que se torna sua fonte quase que exclusiva" (p. 568).

Com outra abordagem, Setton (2010, p. 13) defende que

conceber as mídias como matrizes de cultura é considerá-las um sistema de símbolos com linguagem própria, distinta das demais matrizes de cultura (imagem, som, texto, e a mistura de todos eles) que compõem o universo socializador do indivíduo contemporâneo.

Bévort e Belloni (2009), por sua vez, consideram que as mídias podem ser vistas como dispositivos técnicos de comunicação que atuam tanto no controle social quanto na geração de novos modos de perceber a realidade, 
produzindo e socializando informações e conhecimentos, pois, à medida que difundem determinada forma de cultura, possibilitam a criação de outras.

Podemos considerar, então, que as mídias e a educação são práticas sociais, porque são desenvolvidas no âmbito das relações humanas e criam sentido de uma significação que se constrói à medida que os atores se defrontam e se constituem como sujeitos interlocutores, ou seja, como práticas sociais articuladas na cultura e constituidoras dela ao mesmo tempo (FONSECA, 2004).

As reflexões de Braga e Calazans (2001) quanto à interface dos campos da comunicação e da educação explicitam duas perspectivas: uma de estudo para os meios na escola e outra de leitura crítica dos meios. Para esses autores, ambas "são complementares entre si, e possivelmente envolvidas em um mesmo programa de ação" (p. 59).

Com abordagem similar, Orofino (2005) defende a pedagogia dos meios na escola, configurada como metodologia de leitura crítica, representações sociais e ideologias. Mas a autora ressalta: "Para que uma pedagogia dos meios se efetive como prática educativa crítica no contexto da escola, ela precisa de grupo, coletivo, equipe" (p. 152). Essa proposta de Orofino (2005) provoca-nos algumas indagações:

- Diante dessas abordagens, como entendemos o conceito de mídias? São meios institucionais que transmitem, difundem, criam e valoram comportamentos, ideias e cultura? Ou são meios de criação de cultura pelos diferentes sujeitos sociais?

- Como sujeitos, somos meros reprodutores ou protagonistas de cultura? Qual é o papel da indústria das mídias no contexto atual do Brasil? O que vivenciamos a partir delas, ou para além delas?

Acreditamos que as mídias ultrapassam os instrumentos técnicos, pois desde sempre têm sido utilizadas não apenas como forma de controle mas também como transmissão e criação de comportamentos de ideias e cultura, como já foi dito pelos diferentes sujeitos/atores sociais que dela fazem uso.

Lançadas as inquietações referentes à relação que estabelecemos com as mídias, não podemos deixar de considerar os últimos episódios de manifestação popular no Brasil, em que a maioria das ações fez uso das mídias digitais para o seu cronograma de desenvolvimento. Assim, relacionamos o termo original de cultura com o sentido de cultivar, ou seja, cultivar o desejo de mudança da sociedade, apesar de tantas estratégias de manipulação. Além desse desejo, a cultura é entendida também como arte, tradição, comportamento, refinamento, identidade, entre outros tantos. 
Tendo como aporte o contexto da relação cultura e mídias, remetemo-nos a Setton (2010), que entende a cultura como expressão de um conjunto de condições sociais que envolvem a produção de sentidos e valores, os quais contribuem na reprodução das relações entre os grupos, que auxiliam na transformação e criação de novos sentidos e valores. Por outro lado, Santaella (2003) aponta seis tipos de divisão das eras culturais de formações: a cultura oral, a cultura escrita, a cultura impressa, a cultura de massas, a cultura das mídias ou cultura do disponível e a cultura digital ou cibercultura. Considerando tantas formas de cultura, indaga-se: Estamos neste momento construindo cultura e formando-nos? Ou estamos reproduzindo os discursos e valores veiculados pela indústria da mídia?

Segundo Santaella (2003), em cada momento que surgiu uma cultura, sem extinguir a antecedente, emergiram novos ambientes sociais, novas formas de pensar e agir. Com a cultura digital, estamos construindo novas formas de pensar e agir? Como essas formas influenciam no modo como os estudantes dos cursos de formação de professores lidam com a cultura e a sua produção? As vivências culturais dos estudantes contribuem para que possam refletir e compreender o uso pedagógico crítico das mídias?

MÍDIAS, CULTURA E FORMAÇÃO HUMANA: UMA INTERFACE POSSÍVEL?

No percurso desta reflexão, surgem inquietações acerca da interface proposta, para as quais nem sempre temos respostas prontas. Entretanto, com base nos conceitos anunciados, é possível perceber que a interface valoriza o conceito de "cultura das mídias". Esse conceito é cunhado por alguns estudiosos, como Santaella (2003) e Setton (2010). Para a primeira, o conceito de cultura das mídias está situado na distância entre os conceitos de cultura de massa e cultura virtual, semeado "por processos de produção, distribuição e consumo comunicacionais" (SANTAELLA, 2003, p. 24). Já em Setton (2010), podemos encontrar a mesma abordagem desse conceito, quando a autora ressalta que essa cultura atende às demandas de um público em um contexto social específico.

Ambos os entendimentos remetem-nos às mídias, institucionais ou não, como potencializadoras de possibilidades de produzir culturas e formação humana. No atual contexto, as tecnologias de informação e comunicação e a escola são espaços propulsores de reflexão, cabendo às pessoas perceberem-se como sujeitos protagonistas.

Em seu estudo, Porto (2012, p. 192) ressalta:

A formação docente para apropriação das tecnologias é fundamental, porém entendemos que ela não pode acontecer apenas relacionada à utilidade 
da ferramenta de trabalho, descontextualizada do espaço que se deseja, com ou sem tecnologia, vencendo barreiras, muitas vezes maiores do que a incorporação da tecnologia.

Com esse mesmo entendimento, nos processos de formação docente $^{2}$ que temos desenvolvido, é necessário ressaltar a importância do envolvimento institucional e de seus agentes para que as práticas inovadoras sejam exitosas.

Na configuração da interface anunciada no início desta reflexão, ousamos articular os aspectos indicados pelas pesquisas supracitadas, questionando: Que cultura digital estamos gerando nos processos de formação docente? De acordo com Fantin e Rivoltella (2012), a cultura digital se constitui na convergência de todas as tecnologias de informação e comunicação, na cultura da portabilidade e no consumo da mídia pessoal. A reflexão sobre essa questão retoma outras, tais como: Mídia é cultura? Mídia cria cultura?

A ideia de mídias para além das instituições midiáticas de meios de comunicação relacionados à indústria cultural é denominada por Setton (2010) como matriz cultural. Essa concepção entende as mídias como produtoras de cultura, pois são produzidas por sujeitos imersos em diferentes contextos culturais.

A indicação dessa concepção de mídias coaduna-se com as análises feitas por Fantin e Rivoltella (2012) e é reforçada na conclusão de Porto (2012) acerca dos processos de formação docente em relação ao uso das diferentes tecnologias de informação e comunicação que não se restringem ao "saber operar" tecnologias, ferramentas e aplicativos, mas, sim, desenvolver, além das habilidades técnicas, a reflexão dos sentidos produzidos por elas em relação ao contexto dos sujeitos. As pesquisas supracitadas apontam, ainda, a necessidade de as políticas de formação docente serem articuladas com as de inserção das tecnologias nas escolas e práticas educativas, como assevera Fantin e Rivoltella (2012, p. 138):

Nesse sentido, enfatizamos a necessidade de pensar políticas públicas de inserção das tecnologias nas escolas aliadas às políticas de formação do professor na perspectiva da mídia - educação. Ou seja, que a dimensão do acesso digital possa significar qualidade do acesso e condições de produção como mediação cultural, para que a inclusão digital e tecnológica de estudantes e professores seja também inclusão social e cultural, possibilitando-lhes participação cultural diferenciada, na perspectiva da educação para cidadania.

A análise também apresentada por Porto (2012) indica que a formação docente não pode estar atrelada apenas à utilidade de ferramentas de 
trabalho, descontextualizada do espaço escolar, além, é lógico, de motivar reflexões sobre o modelo de escola que se deseja. Tais entendimentos reforçam o desafio já anunciado por Rodrigues e Barcelos (2011, p. 15):

Um grande desafio para os educadores na contemporaneidade é redirecionar ações que se voltem para um mundo tecnológico do ciberespaço, isso vai além da racionalidade moderna que, ainda, engessa e comprime percepções sobre a construção do conhecimento e do mundo.

Afinal, o desafio de uma formação crítica, reflexiva e protagonista na construção de interfaces dos conhecimentos da educação e da comunicação gera conceitos próprios de cultura e formação, quiçá das mídias como matrizes culturais de sentidos de comunicação educativa.

Afinal, para que é que se aprende? E por que se inventou a educação e, depois, a escola? Como é que isso aconteceu e o que é que se faz ali? Já que "ninguém escapa da educação", seria bom ao menos compreendê-la. Nem sempre houve escola e nem sempre ela foi do jeito que conhecemos. Em vários momentos da história, tipos diversos das sociedades criaram diferentes caminhos para percorrer a estranha aventura de lidar com o saber e os poderes que ele carrega consigo. (BRANDÃO, 1995, contracapa)

Afirmar que um fato ou fenômeno midiático que ocorre no cotidiano é pedagógico pressupõe conceber a educação como um processo caracterizado por múltiplas determinações e permanentemente construído pelo homem. Numa concepção histórica, considera-se a educação como um processo constituído de atividades mediadoras no seio da prática social global. Isto é, podemos afirmar que a educação sempre se refere a uma sociedade concreta e historicamente situada.

Alinhado com essa abordagem, Libâneo (1992) apresenta as seguintes modalidades de educação: formal, não formal e informal. A educação formal é aquela estruturada, organizada e planejada intencionalmente e envolve a educação em diferentes níveis e modalidades, tais como: educação infantil, fundamental, de adultos e outras. A educação não formal consiste em atividades com caráter de intencionalidade, porém com baixo grau de estruturação e sistematização - por exemplo, a educação religiosa. A educação informal refere-se às práticas educativas não intencionais, como a organização social e a família.

De acordo com essa classificação, uma passeata de homossexuais, conforme Libâneo (1992), pode ser considerada uma atividade de educação não formal, pois possui um caráter de intencionalidade, porém com baixo grau de estruturação e sistematização. Segundo o autor, esse evento 
enquadra-se como uma prática pedagógica porque, de um lado, expressa uma luta concreta pelos direitos individuais e coletivos de participação social, contra a exploração e discriminação social, e, de outro lado, inserese no desenvolvimento histórico da sociedade, pois supõe processos educacionais intencionais. Na verdade, uma atividade dessa natureza traz o entrelaçamento das três modalidades de educação, pois expressa o conjunto de conhecimentos, valores e ideias adquiridas pelo homem na sua formação integral. Mesmo uma modalidade de educação informal, como a família, caracterizada pela não intencionalidade, traz no seu cerne exigências e conhecimentos adquiridos em processos intencionais formais e não formais.

Recorremos a um exemplo citado por Libâneo (1992) sobre um fato social para relacioná-lo com o papel da mídia diante desse fato. Conforme o autor, a forma de difusão e veiculação de fatos como a citada passeata de homossexuais pelos meios midiáticos merece um exercício de leitura consciente, ampla e fundamentada, caso contrário corre-se o risco de atuarmos apenas como reprodutivistas do discurso veiculado sem refletir ou buscar conhecer outras versões sobre os referidos fatos.

A luta contra a discriminação sexual, racial ou religiosa revela que, em nenhuma sociedade, a alienação pode ser total e absoluta, uma vez que a contradição que a constitui gera a possibilidade de desvelar e superar a realidade existente. Entendemos, aqui, que uma prática é pedagógica quando se trata de uma ação consciente, intencional e planejada, dirigida ao processo de formação do homem e à construção histórica dos indivíduos e da sociedade.

No intuito de executar uma ação planejada, a prática pedagógica reverte-se em prática de ensino, ou seja, na manifestação peculiar da educação formal escolar. De fato, a educação escolar, via processo ensino-aprendizagem, é a maior manifestação do caráter pedagógico; entretanto, este não pode ser reduzido à instrumentalização das atividades de ensino, haja vista a dimensão da prática pedagógica presente no cotidiano da formação humana, seja nas relações de trabalho, seja nas educativas propriamente ditas. Com essa mesma matriz de pensamento, Braga e Calazans (2001) trazem o termo "aprendizagens mediatizadas" ao relacionar mídia e educação como convergências de práticas e fundamentos voltados à formação crítica, reflexiva e protagonista. Essa configuração de aprendizagens coaduna-se com a proposta de Orofino (2005) de pedagogia dos meios como metodologia para a formação, a qual podemos adotar em processos formais e não formais de educação.

A partir desses entendimentos, concebemos que, apesar de a função social da mídia ser entretenimento e informação, não podemos perder de vista a dimensão política, pois esta não se distingue do caráter social das atividades 
humanas. Podemos dizer que o ato pedagógico também constitui a prática histórica do homem, assim como a mídia, e ambos, por sua vez, constituem práticas educativas. Entretanto, a prática pedagógica formal, desempenhada predominantemente pela escola, aponta para uma visão de totalidade, uma vez que se constitui de nexos que se inserem no desenvolvimento histórico da sociedade.

RELAÇÃO FORMAÇÃO, MÍDIA E CULTURA: O QUE ALGUMAS PESQUISAS REVELAM

A escola é inevitavelmente um lugar de negociação (e com frequência, de luta) entre as concepções concorrentes de conhecimento e o valor cultural. (BUCKINGHAM, 2010, p. 44)

A epígrafe acima traz uma ideia de formação. Além dessa, coexistem as ideias de instrução, habilidades, competências, profissão, cultura e outras.

Nos estudos realizados por Setton (2010), a socialização é considerada uma dimensão da formação humana que possibilita a produção de cultura. Partindo desse pressuposto, podemos dizer que a escola, a família e a mídia são espaços que apresentam estratégias, processos e práticas que expressam, criam e representam visões de mundo e sociedade. Esses espaços, por sua vez, são plurais, de múltiplas referências identitárias e culturais. Essa é uma característica singular da modernidade, que se constitui de sistemas articulados com linguagens híbridas e fragmentadas.

$\mathrm{Na}$ escola, a função formativa implica práticas voltadas para o ensino e que, em um primeiro momento, é a conversão dos conhecimentos humanamente construídos e reconhecidos cientificamente em conhecimentos sistematizados e estruturados. Isto é, de acordo com pressupostos didáticos, converte conhecimentos científicos em conhecimentos teórico-práticos. Num segundo momento e em consequência do primeiro, implica a estruturação e sistematização dos elementos constitutivos do processo de ensino, que não se reduz à matéria ou ao método de ensino, mas constitui um conjunto de princípios teórico-didáticos que, a priori, surgem da intencionalidade política, científica ou social.

No exercício de uma leitura crítica das mídias massivas, constatamos que esse conhecimento via informação é distribuído por meio de ferramentas comunicativas de forma fragmentada e superficial. E a escola, como traduz os conhecimentos científicos em princípios teórico-práticos?

A partir da pesquisa realizada por Fantin e Rivoltella (2012) em escolas de Milão e de Florianópolis, ${ }^{3}$ percebemos as tensões no processo de formação docente, o qual envolve a carreira do magistério, as condições de 
trabalho, o desejo e a necessidade de formação continuada, as políticas de inserção das tecnologias nas escolas articuladas com as políticas de formação, as dificuldades de mudanças culturais. Enfim, a pesquisa conclui que a cultura digital é o marco mais significativo da sociedade atual e apresenta três sentidos desafiadores: a passagem do lugar físico ao lugar social, a mudança do papel da escola e as diferentes formas de aprendizagens.

O estudo de Araújo (2013) explora a pedagogia dos meios delineada por Orofino (2005), que, conforme visto anteriormente, propõe uma prática metodológica que sintetiza as diferentes iniciativas críticas de leitura e formação para as mídias já desenvolvidas no Brasil.

Segundo o autor,

Nesta proposta, a tecnologia não tem um fim em si mesma, mas é uma forma para que as crianças e adolescentes possam atribuir novos significados ao mundo através da produção de conhecimento. Isto significa dizer que a tecnologia não deve ser utilizada meramente como recurso didático, de modo instrumental. Para que auxilie a transformar as relações educativas, a tecnologia deve estar atrelada a realidade sociocultural dos estudantes. (ARAÚJO, 2013, p. 22)

Araújo (2013) conclui, ainda, que outra contribuição da Pedagogia dos meios é a prática protagonista por parte dos alunos e mediadora por parte do professor, estabelecida a partir da utilização da tecnologia na escola. Essa prática permite que os alunos se sintam inseridos nas mídias, ou seja, eles passam a vê-las de forma contextualizada e na perspectiva da visibilidade da cultura local. Além disso, Araújo destaca que essa proposta permite que o professor articule as várias disciplinas, isto é, a interdisciplinaridade do currículo escolar, incluindo ainda outros assuntos de interesse dos alunos.

Encontramos na pesquisa de Porto (2012) resultados que apontam o esforço do professor para aceitar e apropriar-se das inovações que chegam à escola. Ao afirmar que "o professor não recusa a mudança" (p. 184), Porto apresenta "estratégias de sobrevivência", as quais são práticas pedagógicas geradas para assegurar o acompanhamento e o controle da relação pedagógica. Nessa relação, ora emergem práticas tradicionais de âmbito diretivo e controlador, ora práticas inovadoras de cunho colaborativo e integrador.

\section{PARA NÃO ENCERRAR: APRENDIZAGEM, MÍDIAS E FORMAÇÃO}

A partir das pesquisas, estudos e processos formativos realizados até o momento em torno da temática abordada neste artigo, entendemos que não cabem às mídias pedagogizar as informações, porém as estratégias 
de linguagem utilizadas para seduzir, convencer, generalizar e unificar as diferentes culturas, formas de pensamento e de entendimento da realidade contribuem para uma prática de educação não formal difusa e ao mesmo tempo eficaz.

A educação escolar e a prática social não são meros processos que coexistem, pois uma age sobre a outra, exercendo influências e conexões que se encontram veladas pela realidade objetiva. Logo, o trabalho docente compreende a formação e o desenvolvimento da personalidade dos indivíduos, o que os remete para a atividade social e para uma atuação de protagonista, no sentido de discernir, selecionar, avaliar o que é difundido pelas mídias, mas, ao mesmo tempo, sem perder de vista que estas são também uma produção cultural.

A relação intrínseca entre as modalidades de educação formal, não formal e informal presentes nos espaços da escola, da família e das mídias, e as contradições e antagonismos das condições concretas da sociedade envolvem, além de uma postura crítica, a participação política e a cultural.

Nesse sentido, o professor - pela sua formação acadêmica de cunho pedagógico - dispõe de elementos que permitem o conhecimento das capacidades intelectuais do educando, bem como está apto para articular, à matéria de ensino, o conhecimento já adquirido pelo indivíduo na vida social, seja de maneira formal, não formal ou informal.

Esse movimento remete-nos à interface da relação entre mídia, cultura e formação docente, discutida neste artigo, principalmente no questionamento do que essa interface representaria. Assim, a alusão que o termo confere à trilogia trabalhada, ou seja, mídia, cultura e formação docente, é da configuração de uma relação mútua, em que pode haver ou não a predominância de um dos campos de conhecimento sobre os outros nos processos de produção e prática social, além dos processos formativos.

MEDIA, CULTURE AND FORMATION

ABSTRACT:This article is the result of a literature review undertaken by the author in the 'Study and Research of new Technologies and Education' group in the Department of Education at the Universidade Federal de Goiás. The aim of this group is to reflect on the possibility of Pedagogy students relating the different theoretical aspects involved in the media with the cultural experiences they provide so that they can later think out this relationship pedagogically. This reflection is based on a multiple concept of media as "means of communication" and cultural matrices, as culture related to a system of meanings and to the image of constructing identity; and as human formation which is established in the relationship between formal and informal, and through different 
languages. Its sets out to reflect on this trilogy using the relationship between theory and practice of cultural media experiences in teacher formation processes.

Key words: Media. Culture. Teacher formation.

\section{MEDIOS, CULTURA Y FORMACIÓN}

Resumen: Este artículo es el resultado de la investigación bibliográfica desarrollada por las autoras en el Grupo de Estudios e Investigaciones Nuevas Tecnologías y Educación-GENTE, de la Facultad de Educación de la Universidad Federal de Goiás, del cual ellas participan y que tiene como objetivo reflexionar sobre la posibilidad de que los estudiantes de pedagogía relacionen los diferentes aspectos teóricos involucrados en los medios de comunicación con las experiencias culturales que tienen con ellas, para, a continuación, pensar pedagógicamente esa relación. Esa reflexión se basa en un múltiple concepto de medios como "medios de comunicación" y las matrices culturales; como cultura relacionada con un sistema de significados y con la imagen de la construcción de la identidad; y como formación humana, que se establece en la relación entre lo formal y lo no formal y por medio de los diferentes lenguajes. Por último, hemos tratado de reflejar esa trilogía, a partir de la relación entre la teoría y la práctica de las experiencias culturales mediáticas en los procesos de formación Docente.

Palabras claves: Media. Cultura. Formácion del profesorado.

\section{NOTAS}

1. Educação formal: intencional, com objetivos explícitos em instituições educacionais; educação não formal: intencional, desenvolvida em espaços não escolares, como em cursos de aperfeiçoamento em empresas e outros; educação informal: não intencional e nem organizada, ocorre espontaneamente, como na família, no convívio com os amigos e outros.

2. Projetos de pesquisa: Infovias e Educação (UFG/FE, 2001/2002); Reducativa (UFG/FE, 2003-2005); Leitura crítica das mídias a partir das redes sociais (UFG/FACOMB, 2012). Projeto de Extensão: Processos de inclusão social: interfaces da inclusão digital (UFG/ FE, 2011). Disciplina no curso de Pedagogia: Educação, comunicação e mídias (UFG/FE).

3. Pesquisa realizada no período de 2008 a 2010, que buscou compreender quais os conteúdos, as formas e as possibilidades da formação de professores diante dos desafios da cultura digital e as práticas culturais de uso, consumo, apropriação e produção das mídias. 


\section{REFERÊNCIAS}

ARAÚJO. J. M. A pedagogia dos meios: um estudo preliminar. Curso de Pedagogia. Universidade Federal de Goiás/Faculdade de Educação. Trabalho de Conclusão de Curso FE/UFG, 2013.

BÉVORT, E.; BELLONI, M. L. Mídia-educação: conceitos, história e perspectivas. Educação \& Sociedade, v. 30, n. 109, 2009. Disponível em: <http://www.scielo.br/scielo. php?pid=S0101-73302009000400008\&script=sci_arttext>. Acesso em: 2 fev. 2014.

BRAGA, J. L.; CALAZANS, R. Comunicação e educação. São Paulo: Hacker, 2001.

BRANDÃO, C. R. O que é educação. 33. ed. São Paulo: Brasiliense, 1995.

BUCKINGHAM, D. Cultura digital, educação midiática e o lugar da escolarização. Educação e Realidade, Porto Alegre, v. 35, n. 3, p. 37-58, set./dez. 2010. Disponível em: <http://www.ufrgs.br/edu_realidade>. Acesso em: 10 jun. 2013.

FANTIN, M.; RIVOLTELLA, P.C. Cultura digital e formação de professores: usos da mídia, práticas culturais e desafios educativos. In: . (Orgs.). Cultura digital e escola: pesquisa e formação de professores. Campinas, SP: Papirus, 2012.

FONSECA, C. C. Os meios de comunicação vão à escola? Belo Horizonte: Autêntica, 2004.

GUARESCHI, P. A “mercadoria” informação: um estudo sobre comerciais de TV e rádio. Paidéia, n. 18, v. 41, p. 567-580, 2008. Disponível em: <http://www.scielo.br/paideia>. Acesso em: 12 dez. 2013.

LIBÂNEO, J. C. Os significados da educação, modalidades de prática educativa e organização do sistema educacional. Inter-Ação, n. 16, v. 1-2, p. 35-46, jan./dez. 1992.

OROFINO, Maria Isabel. Mídias e mediação escolar: pedagogia dos meios, participação e visibilidade. São Paulo: Cortez, 2005.

PORTO, T. M. S. As tecnologias estão nas escolas. E agora, o que fazer com elas? In: FANTIN, M.; RIVOLTELLA, P. C. (Orgs.). Cultura digital e escola: pesquisa e formação de professores. Campinas, SP: Papirus, 2012.

RODRIGUES, C. A. C.; BARCELOS, S. Olhares e reflexões sobre as mídias. Revista ĺcone, São Luis de Montes Belos, 2011. Disponível em: <http://www.slmb.ueg.br/iconeletras/ index.html>. Acesso em: 10 jul. 2012.

SANTAELLA, L. Da cultura das mídias à cibercultura: o advento do pós-Humano. Revista Famecos, Porto Alegre, n. 22, p. 23-32, 2003.

SETTON, M. da G. Mídia e educação. São Paulo: Contexto, 2010. 
Daniela da Costa Britto Pereira Lima é licenciada em Pedagogia, especialista em Avaliação Educacional, mestre em Educação e doutora em Políticas Públicas, Estratégias e Desenvolvimento. É professora do curso de Pedagogia e do Mestrado Interdisciplinar em Educação, Linguagem e Tecnologias.

E-mail:professoradanielalima@gmail.com

Cleide Aparecida Carvalho Rodrigues é licenciada em Pedagogia, especialista em Metodologia do Ensino Superior, mestre e doutora em Educação. É professora da Faculdade de Educação da UFG.

E-mail: cleideacr@smail.com 